\title{
Elucidating the Pozzolanic Characteristics of Pastes Containing Circulat- ing Fluidized Bed Fly Ash
}

\author{
Kae-Long Lin ${ }^{1, *}$, Chao-Lung Hwang ${ }^{2}$ and Yu-Min Chang ${ }^{3}$ \\ ${ }^{I}$ Department of Environmental Engineering, National Ilan University, No. 1, Sec.1, Shen-Lung Rd., Yilan, 26047, \\ Taiwan, $R O C$ \\ ${ }^{2}$ Department of Construction Engineering, National Taiwan University of Science and Technology, Keelung Rd., Sec. 4, \\ Taipei 106, Taiwan, ROC \\ ${ }^{3}$ Institute of Environmental Engineering and Management, National Taipei University of Technology, Taipei 106, \\ Taiwan, $R O C$
}

\begin{abstract}
The aim of this study is to investigate the pozzolanic characteristics of circulating fluidized bed fly ash blended cement (CFBFABC) paste containing circulating fluidized bed fly ash (CFBFA). The initial and final setting time of CFBFABC pastes with CFBFA retards with an increasing CFBFA content. CFBFABC pastes containing 10\% CFBFA exhibited a compressive strength similar to that of ordinary Portland cement pastes at the ages of 90 days. X-ray diffraction peaks indicated the presence of portlandite, ettringite, and unreacted $\mathrm{C}_{3} \mathrm{~S}\left(32.6^{\circ}\right)$ and $\mathrm{C}_{2} \mathrm{~S}\left(41.9^{\circ}\right)$. The gel/space ratio of the CFBFABC pastes increased with the curing time and decreased as the CFBFA content increased. The gel/space ratio increased with the curing time because of the progress of hydration, which led to some of the pores being filled. At the ages of 90 days, the gel/space ratio of the CFBFABC pastes containing $10 \%$ CFBFA increased to approximately $14 \%$, it is possibly the consumption of $\mathrm{Ca}(\mathrm{OH})_{2}$ and the formation of $\mathrm{C}-\mathrm{S}-\mathrm{H}$ in the CFBFABC pastes. The CFBFABC pastes containing $10 \%$ CFBFA did not exhibit any major decrease in the gel/space ratio. It exhibited favorable mechanical characteristics that were observed when the mixing ratio of CFBFA was $10 \%$. Furthermore, CFBFA has the potential, as a pozzolanic material, partially to replace ordinary Portland cement.
\end{abstract}

Keywords: Circulating fluidized bed fly ash, compressive strength, gel/space ratio, hydration, Pozzolanic, setting time.

\section{INTRODUCTION}

Circulating fluidized bed combustion (CFBC) is an effective technology for high-sulfur coal burning, and $\mathrm{SO}_{2}$ can be captured by adding limestone in situ during combustion [1, 2]. High-sulfur petroleum coke is a byproduct of the highsulfur oil refining industry. Because of its high calorific value, it is often used as fuel along with coal in CFBC [3]. In a circulating fluidized bed (CFB) boiler, energy is generated by burning petroleum coke. To prevent the emission of a large amount of sulfur dioxide from blazed petroleum coke with a high sulfur content, limestone is introduced to the boiler for desulfurization. To increase the $\mathrm{SO}_{2}$ removal efficiency, the $\mathrm{CaO} / \mathrm{SiO}_{2}$ ratio is often increased to 2.0-2.5. Moreover, there are many unreacted $(\mathrm{CaO})$ and desulfurized $\left(\mathrm{CaSO}_{4}\right)$ products, and a small amount of $\mathrm{CaCO}_{3}$ remains in the fly ash and bed ash of CFBC [1]. CFBC ash is produced at low combustion temperatures of $800-1000{ }^{\circ} \mathrm{C}$; therefore, it may exhibit lower pozzolanic activity than does fly ash produced at higher temperatures [4].

In Taiwan, the petroleum industry produces approximately 800,000 tons of CFBC ash annually [5]. Recently,

*Address correspondence to this author at the Department of Environmental Engineering, National Ilan University, No. 1, Sec.1, Shen-Lung Rd., Yilan, 26047, Taiwan, ROC; Tel: +886-3-9357400ext 749; Fax: +886-3-9364277; E-mail: kllin@niu.edu.tw. energy saving and carbon reduction have been focuses worldwide, and thus, the concept of sustainable development has become popular. Emphasis on environmental protection has increased worldwide. Consequently, state-of-the-art research has focused on recycling and reusing industrial byproducts. Currently, a wide range of construction-related industrial byproducts, including fly ash, silica fume, and water quenching slag, are used as cementing material to reduce cement consumption [6]. Pozzolans, when used as a partial cement replacement, are thought to improve the resistance of mortar or concrete to sulfate attack. The principal chemical effect of a pozzolan present in mortar is the removal of $\mathrm{Ca}(\mathrm{OH})_{2}$ from the hydrating cement paste, leading to the formation of additional cement gel. In the case of a sulfate attack, upon exposure to a $\mathrm{Na}_{2} \mathrm{SO}_{4}$ solution, $\mathrm{Ca}(\mathrm{OH})_{2}$ depletion in mortar is advantageous because $\mathrm{Ca}(\mathrm{OH})_{2}$ provides $\mathrm{Ca}^{2+}$ ions for ettringite and gypsum formation, leading to the expansion and degradation of the mortar [7]. Previous investigations have indicated that CFB fly ash along with pressured fluidized bed combustion ash or pulverized fuel ash can be used to prepare cementless concrete [8-10]. Sheng's [11] investigation of the cementitious properties of fly ash produced by CFBC boilers cofiring coal and highsulfur petroleum coke revealed that a high $f$-CaO content and a high $\mathrm{SO}_{3}$ content enhance cementitious properties; in other words, CFB fly ash is cementitious [12]. Freidin [13] indicated that a high total $f-\mathrm{CaO}$ and $\mathrm{Ca}(\mathrm{OH})_{2}$ content and high 
$\mathrm{SO}_{3}$ content contribute to a gradual increase in the compressive strength of fly ash and that curing significantly affects the strength of fly ash. Waste materials have traditionally been discarded in landfills and often dumped directly into ecosystems without adequate treatment. However, possible reuse or recycling alternatives should be investigated and implemented. The recent environmental approach aims to achieve sustainable development by conservation of natural resources and minimizing the discard of materials. Today, the reuse and recycling of waste materials after their potentialities have been detected is considered an activity that can contribute to diversify products, reduce production costs, provide alternative raw materials for a variety of industrial sectors, conserve non-renewable resources, save energy, and especially, improve public health [14]. Accordingly, this study evaluated the effect of CFB fly ash blended cement (CFBFABC) pastes on the pozzolanic reaction of CFB fly ash when the paste is adopted as a partial substitute for cement. Microstructural studies were conducted using X-ray diffraction (XRD) and gel/space ratios analyses.

\section{MATERIALS AND METHODOLOGY}

\section{Materials}

The CFBFA was obtained from a power plant in Taiwan. The CFBFA was homogenized; oven dried at $105^{\circ} \mathrm{C}$ for 24 hours; and then the chemical composition was characterized. American Society for Testing and Materials (ASTM) Type I Portland cement (OPC) from the Taiwan Cement Company was used in this study. It had a specific gravity was 3.15 and its physical-chemical properties met the requirements of ASTM C150. The major composition of the OPC is shown in Table $\mathbf{1}$.

Table 1. Chemical composition of CFB fly ash.

\begin{tabular}{|c|c|}
\hline Chemical Composition (\%) & CFB Fly Ash \\
\hline \hline $\mathrm{SiO}_{2}$ & 2.62 \\
\hline $\mathrm{Al}_{2} \mathrm{O}_{3}$ & 0.99 \\
\hline $\mathrm{Fe}_{2} \mathrm{O}_{3}$ & 0.52 \\
\hline $\mathrm{CaO}$ & 51.95 \\
\hline $\mathrm{MgO}$ & 1.26 \\
\hline $\mathrm{SO}_{3}$ & 25.74 \\
\hline
\end{tabular}

\section{Preparation of CFBFA}

The CFBFA was then further pulverized in a ball mill until the particles could pass through a \#200 mesh sieve. The CFBFA had a fineness value (on Blaine) of approximately $300 \mathrm{~m}^{2} / \mathrm{Kg}$, with a specific gravity of 2.54 . The resultant pulverized CFBFA was desiccated before being tested.

\section{Preparation of CFBFA Blended Cement Paste Specimens}

CFB fly ash blended cement (CFBFABC) pastes were produced by homogeneously mixing cement and water in a mixer. The levels of CFBFA substitution in the blended cement were between 10 and $40 \%$ by weight of the cement.
The water/binder $(\mathrm{w} / \mathrm{b})$ ratio of the CFBFABC paste was a constant of 0.4. CFBFABC paste cubes were prepared according to ASTM C109. The CFBFABC paste was poured into rectangular molds, which were kept under ambient conditions for 24 hours before being de-molded. After curing for 7, 14, 28, 56 and 90 days, the samples were subsequently crushed. Finally, the prepared samples were subjected to Xray Diffraction (XRD) and gel/space ratios analyses.

\section{Analysis Methodology}

The major analyses performed on the CFBFABC pastes and its cube specimens included the following:

(1) Setting time: The setting times of the cement mixes were determined according to ASTM C191 using a Vicat apparatus at room temperature. The initial setting time occurred when a Vicat needle $1 \mathrm{~mm}$ in diameter penetrated the sample to a point $5 \pm 1 \mathrm{~mm}$ from the bottom of the mould. The final setting time was defined as when a 5-mm cap ring would leave no visible mark when placed on the surface of the sample.

(2) Unconfined compressive strength (ASTM C39-72): At each testing age, four specimens were taken out of the moist room. The surfaces of the specimen were polished to make the two bearing surfaces flat and parallel. Three specimens were used for the compressive strength tests and one for the microstructural examination. The average strength value of the three specimens is presented. The coefficient of variation of these results was less than $10 \%$.

(3) Toxic characteristic leaching procedure (TCLP): SW 846-1311.

(4) Leaching concentration: Cd (SW 846 -7131A), Pb (SW 846 -7421), Zn (SW 846-7951), Cu (SW846-7211), Cr (SW846-7191)

(5) Mineralogy: The XRD analyses were carried out by a Siemens D-5000X-ray diffractometer with $\mathrm{CuK} \alpha$ radiation and $2 \theta$ scanning, ranging between $5^{\circ}$ and $70^{\circ}$. The XRD scans were run at $0.05^{\circ}$-increments, with a $1 \mathrm{sec}$ counting time.

(6) Gel/space ratios and degree of hydration: The degree of hydration of the CFBFABC pastes was determined by thermal analysis. Thermogravimetric analysis instrument was employed to determine the hydration degree of the CFBFABC paste samples using the ignition method. The hydration degree of the CFBFABC pastes was then calculated as follows:

$$
\begin{aligned}
& \alpha=\frac{\left(W_{105}-W_{580}\right)+0.41\left(W_{580}-W_{1007}\right)}{n W_{1007}} \times 100 \% \\
& X=\frac{0.68 \alpha}{0.32 \alpha+W /(C+P)},
\end{aligned}
$$

where

$$
\alpha \text { : Hydration degree, } \% \text {; }
$$

$\mathrm{X}: \mathrm{Gel} / \mathrm{space}$ ratio, \%;

$\mathrm{n}$ : Evaporated water in the completely hydrated specimen; the $\mathrm{n}$ is equal to 0.24 for ordinary Portland cement paste; 


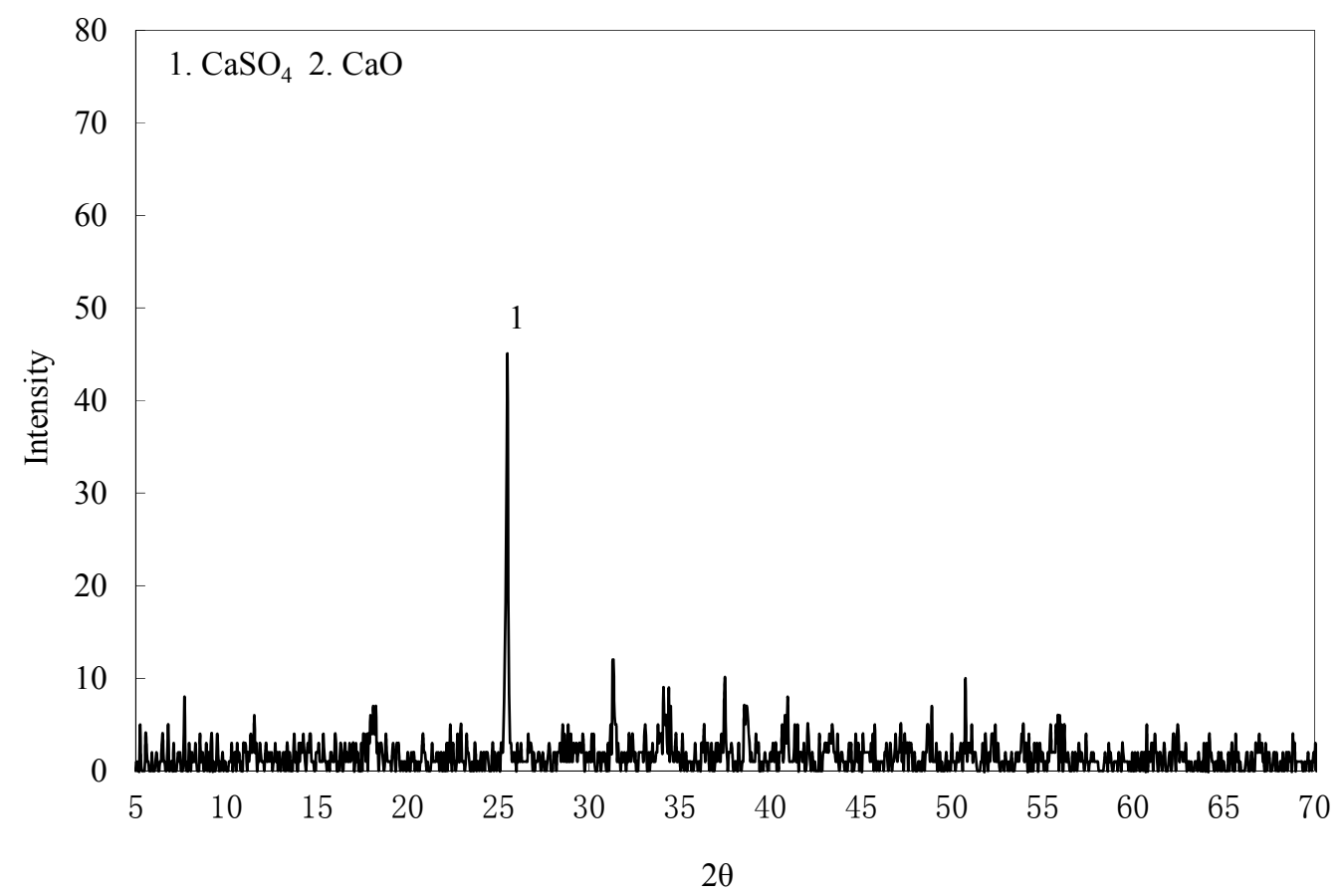

Fig. (1). XRD patterns of CFB fly ash.

Table 2. Heavy metals content and TCLP leaching concentrations of CFB fly ash.

\begin{tabular}{|c|c|c|c|}
\hline Fly Ash & Total Metal (mg/kg) & TCLP (mg/L) & Regulatory Limits \\
\hline \hline $\mathrm{Pb}$ & $35.7 \pm 1.1$ & $0.25 \pm 0.01$ & 5.0 \\
\hline $\mathrm{Cd}$ & $\mathrm{ND}$ & $\mathrm{ND}$ & 5.0 \\
\hline $\mathrm{Cr}$ & $\mathrm{ND}$ & $\mathrm{ND}$ & 5.0 \\
\hline $\mathrm{Cu}$ & $11.9 \pm 1.2$ & $0.013 \pm 0.002$ & - \\
\hline $\mathrm{Zn}$ & $\mathrm{ND}$ & $\mathrm{ND}$ & - \\
\hline $\mathrm{Ni}$ & $345.2 \pm 6.7$ & $\mathrm{ND}$ & \\
\hline
\end{tabular}

$\mathrm{W}_{105}, \mathrm{~W}_{580}, \mathrm{~W}_{1007}$ : Sample weights at 105,580 , and $1007^{\circ} \mathrm{C}$, respectively, $\mathrm{g}$;

41: Mass ratio was $1 \mathrm{~mol} \mathrm{H}_{2} \mathrm{O}$ to $1 \mathrm{~mol} \mathrm{CO}_{2}$;

$\mathrm{W}$ : Amounts of water, \%;

$\mathrm{C}$ : Amounts of cement, \%;

P: Amounts of CFBFA.

\section{RESULTS AND DISCUSSION}

\section{Chemical Characteristics of CFB Fly Ash}

The major components of CFB fly ash are presented in Table 1. The chemical composition of the CFB fly ash was as follows: $51.95 \% \mathrm{CaO}, 25.74 \% \mathrm{SO}_{3}$ and $2.62 \% \mathrm{SiO}_{2}$. Fig. (1) shows the speciation of CFB fly ash, as determined using XRD techniques. It indicated that the major component was $\mathrm{CaSO}_{4}\left(\mathrm{SiO}_{2}\right)$. Heavy metals content and TCLP leaching concentrations of CFB fly ash were listed in Table 2. The leaching concentrations of the CFB fly ash all met the current regulatory thresholds of the Taiwan EPA.

\section{Setting Times of CFBFABC Pastes}

Fig. (2) shows the setting times of the CFBFABC pastes. Wide variability was observed in the setting behavior of the pastes, with the initial times being in the range $4 \mathrm{~h}$ and 11 min to $5 \mathrm{~h}$ and the final times being in the range $6 \mathrm{~h}$ and 15 $\min$ to $7 \mathrm{~h}$. The initial and final setting times of the CFBFABC pastes containing 10\% CFBFA were 366 and 465 min, and those of the CFBFABC pastes containing $40 \%$ CFBFA were 427 and $540 \mathrm{~min}$, respectively. The results of the tests indicated that the initial and final setting times of the CFBFABC pastes exceeded those of an OPC paste. CFBFA is usually used in cement as admixture which increases the fluidity and delays the setting time. The initial setting time of CFBFABC pastes with CFBFA retards with an increasing CFBFA content. The major mineralogical compositions of CFBC fly ash are lime $(\mathrm{CaO})$, sulfuric acid 


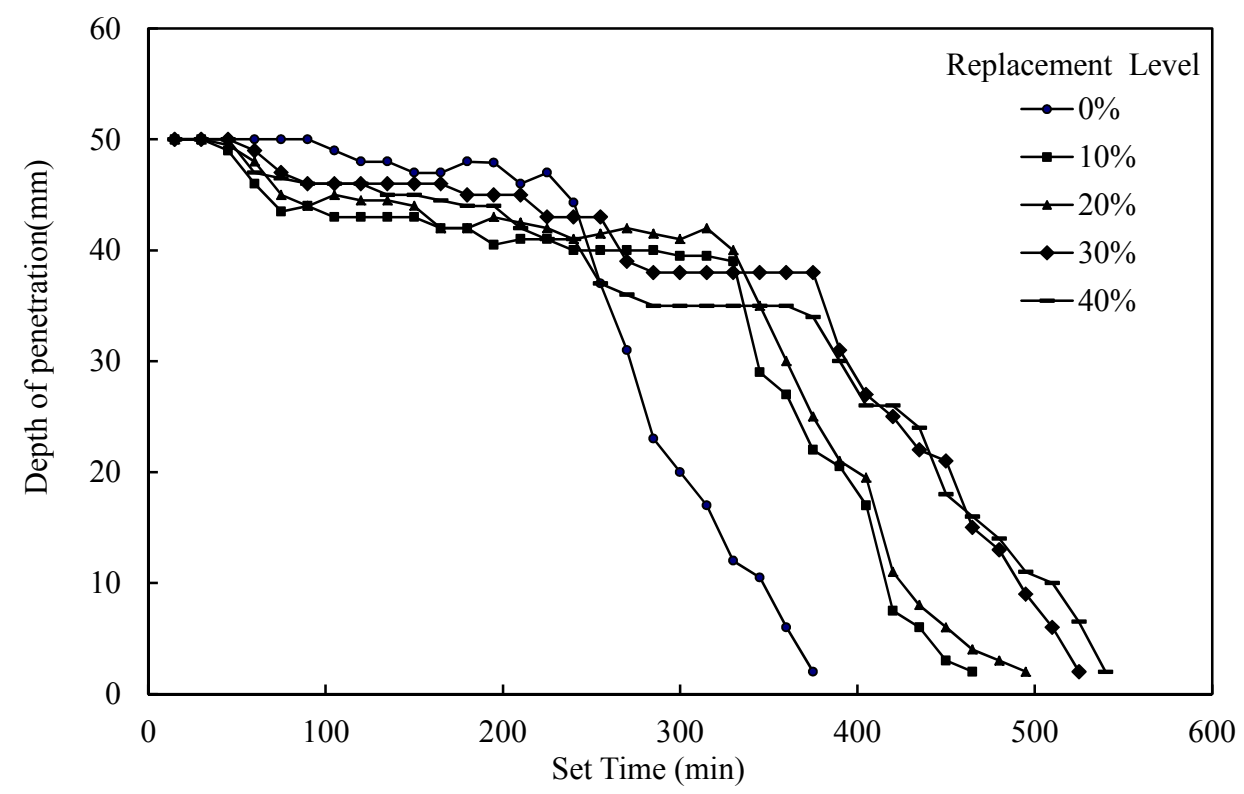

Fig. (2). Setting times of CFBFABC pastes.

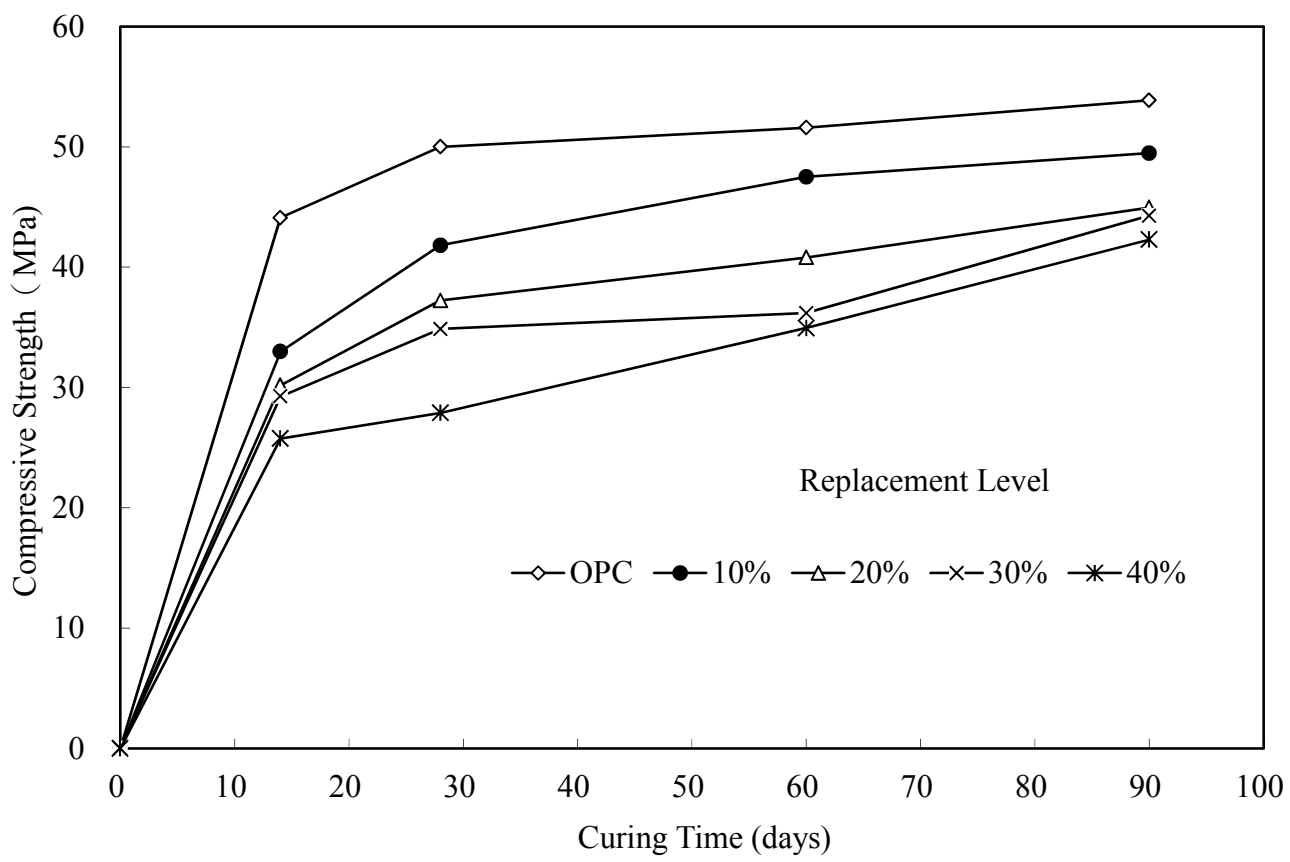

Fig. (3). Compressive strength development of CFBFABC pastes at various ages.

$\left(\mathrm{SO}_{3}\right)$, a-quartz $\left(\mathrm{SiO}_{2}\right)$, and portlandite $\left(\mathrm{Ca}(\mathrm{OH})_{2}\right)$. Thus, CFBC fly ash can be used as a setting retarder replacing gypsum $[15,16]$ due to its high free lime and anhydrite content.

\section{Compressive Strength Development of CFBFABC Pastes}

Fig. (3) shows compressive strengths of CFBFABC pastes. The figure shows the effect of the CFBFA contents on the strength development of the paste. The paste strength clearly decreased as the CFBFA content was increased. When 28 days of curing, the compressive strength of CFBFABC pastes containing $10 \%, 20 \%, 30 \%$, and $40 \%$
CFBFA exhibited $16 \%, 26 \%, 30 \%$, and $44 \%$ decreased, respectively. At the ages of 90 days, compressive strength of CFBFABC pastes containing 10\%, 20\%, 30\%, and $40 \%$ CFBFA exhibited $11 \%, 16 \%, 19 \%$, and $22 \%$ decreases. At the ages of 90 days, the CFBFABC pastes containing $10 \%$ CFBFA exhibited a compressive strength similar to that of OPC pastes. The strength variation implied that changes in the gel content and the effects of the microstructural changes induced occur when CFBFA is substituted for cement. The CFBFABC pastes containing 40\% CFBFA exhibited the lowest compressive strength at all curing time. The chemical compositions, amorphous and crystalline mineral phases of 


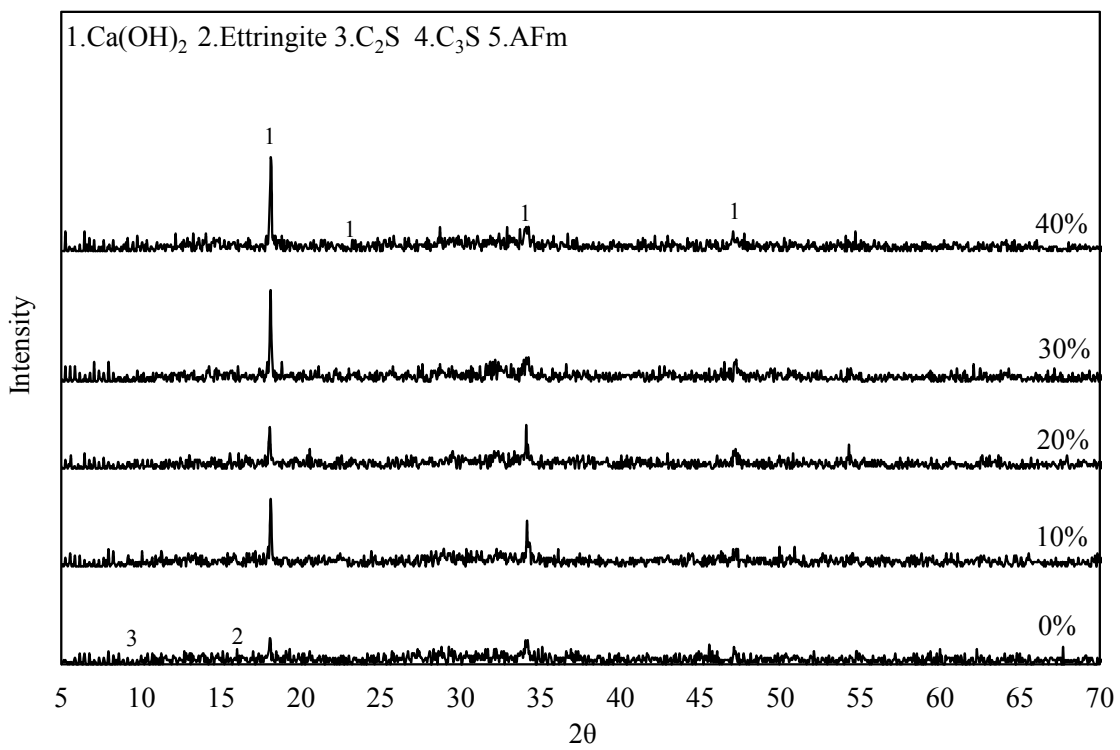

Fig. (4). XRD patterns of CFBFABC pastes at the ages of 28 days.

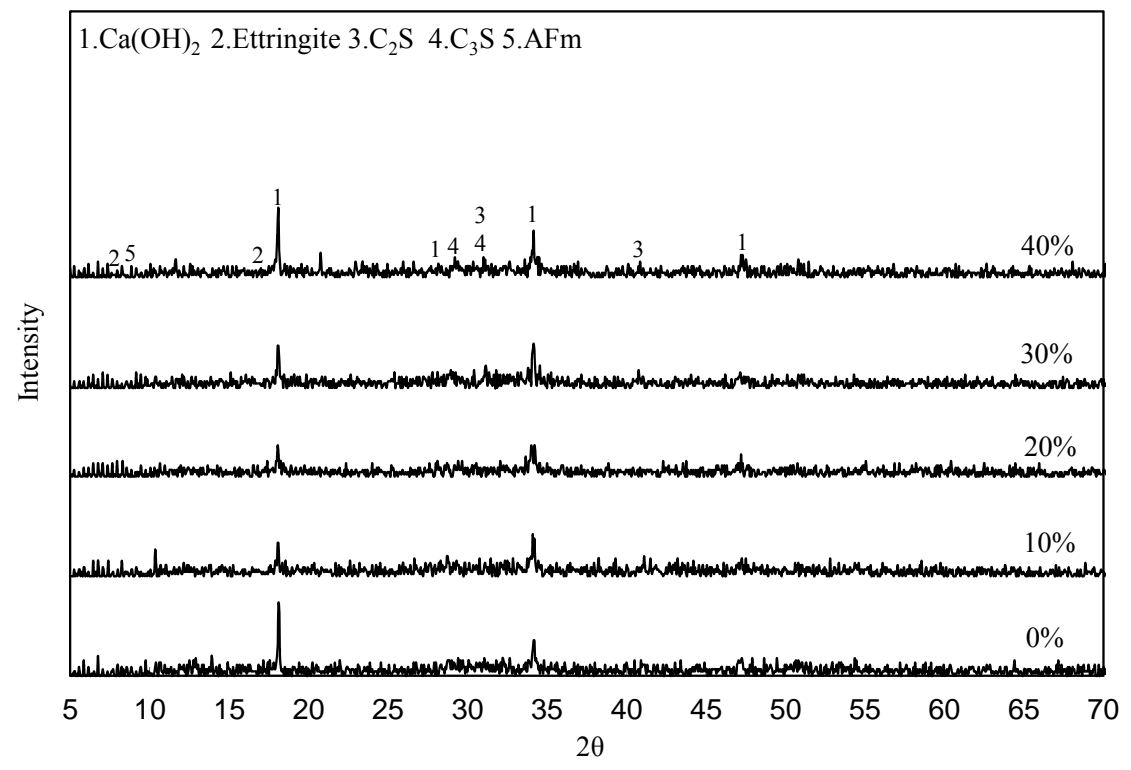

Fig. (5). XRD patterns of CFBFABC pastes at the ages of 90 days.

raw materials have significant influence on the strength development. The degree of reaction and the strength of subsequent crystalline mineral phases of hydrated mixture by CFBFA were lower than that of Portland cement. Thus, adding CFBFA to replace OPC reduced the compressive strength. These results are in agreement with $\mathrm{Wu}$ et al., in which CFBFA was used to partially replace cement in producing cement-based composites [17].

\section{XRD Patterns of CFBFABC Pastes}

Figs. (4) and (5) plot of the XRD patterns of CFBFABC pastes containing 0\%-40\% CFBFA cured for 28 and 90 days. The peaks indicated the presence of portlandite $\left(2 \theta=17.8^{\circ}\right.$, $34.1^{\circ}$, and $\left.47.8^{\circ}\right)$, ettringite $\left(2 \theta=14.08^{\circ}\right.$ and $\left.17.6^{\circ}\right)$, and unreacted $\mathrm{C}_{3} \mathrm{~S}\left(32.6^{\circ}\right)$ and $\mathrm{C}_{2} \mathrm{~S}\left(41.9^{\circ}\right)$. Free lime reacted with silica, forming $\mathrm{C}-\mathrm{S}-\mathrm{H}$ and calcium sulfoaluminate hydrates. The aforementioned constituents differ from those of unreacted and partially reacted CFBFA, and they may reflect the composition of the pozzolanic reaction products. The $\mathrm{XRD}$ results (Fig. 5) indicated that the main hydration products were portlandite, gypsum, and AFt and are consistent with the results of Sheng et al. [11]. The higher $\mathrm{SO}_{3}$ content in pastes may produce excessive ettringite (AFt) and leads to the expansion and disintegration of specimens. The formation of portlandite is attributed to the hydration of lime, and the formation of gypsum is attributed to the hydration of anhydrite; AFt is formed through the following reaction.

$$
3 \mathrm{CH}+3 \mathrm{CSH}_{2}+\mathrm{A}+23 \mathrm{H}=\ddot{\mathrm{y}} \mathrm{C}_{3} \mathrm{~A} .3 \mathrm{CS} . \mathrm{H}_{32}
$$

Here, $\mathrm{A}$ is the active alumina in CFBFA, and AFt is crucial for the hardening and compressive strength development 


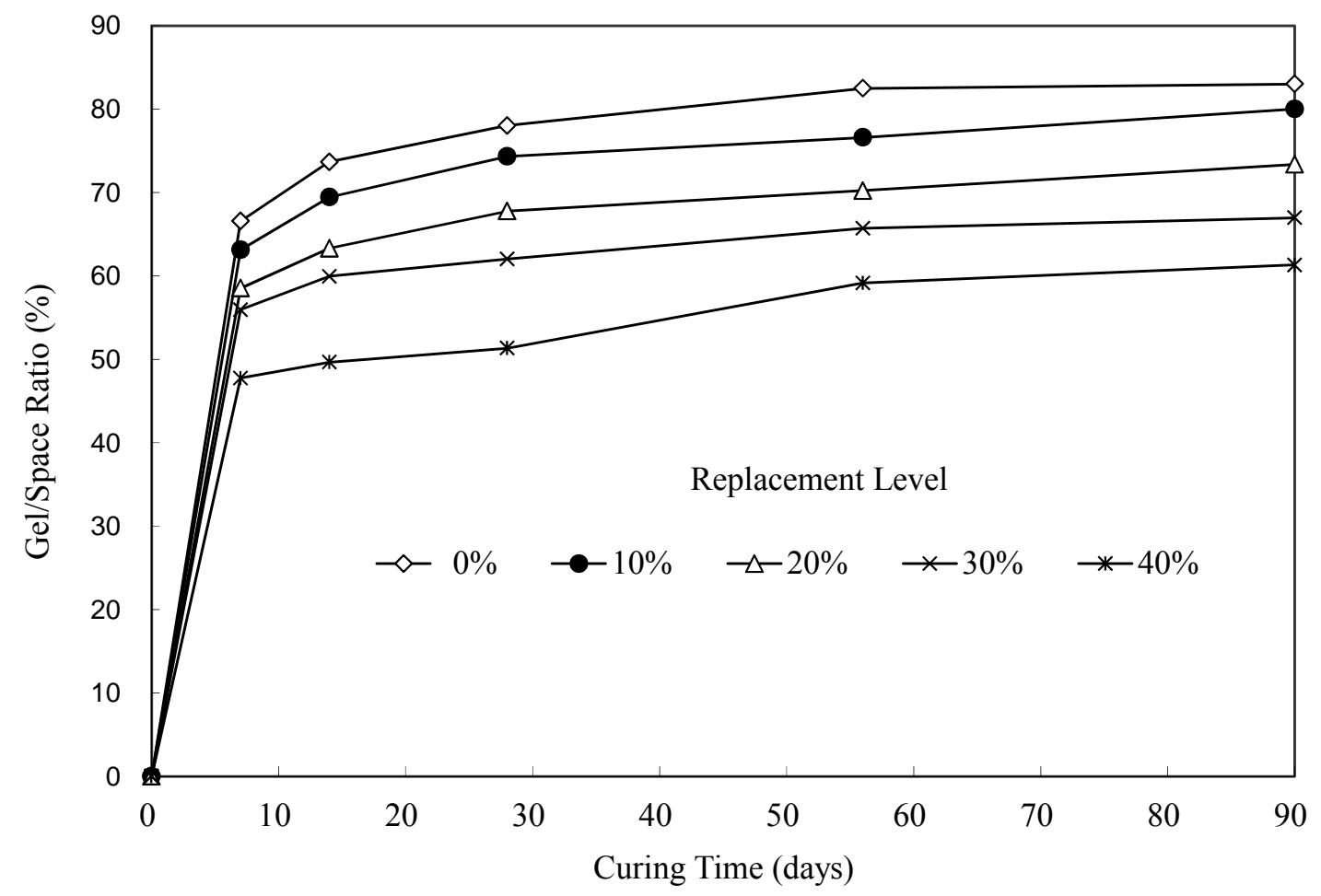

Fig. (6). Gel/space ratios of the CFBFABC pastes.

of a CFBFA-water system. Furthermore, the intensity of the XRD peaks of the unhydrated phases of $\mathrm{C}_{2} \mathrm{~S}$ and $\mathrm{C}_{3} \mathrm{~S}$ decreased when the curing time was increased because of the continuous hydration of these phases.

\section{Gel/Space Ratios of CFBFABC Pastes}

When the gel/space ratio is increased, the amount of hydration products increases; consequently, the synergistic effect of hydration products formed in the pores of the cement pastes enhances the compressive strength [12]. Fig. (6) shows the gel/space ratios of the CFBFABC pastes. The gel/space ratios increased with the curing time and decreased as the CFBFA content increased. The products of CFBFABC pastes, including hydrates of calcium silicate (CSH), ettringite, and Afm, were also expected to form with the consequent consumption of $\mathrm{Ca}(\mathrm{OH})_{2}$. The gel/space ratios increased with the curing time, which led to part of the pores being filled. In addition, the gel/space ratios of the CFBFABC pastes decreased to a greater extent than did those of the OPC pastes. The volume change in $\mathrm{SiO}_{2}$ in a pozzolanic reaction is caused by the production of $\mathrm{CSH}$, it is possibly the low density of the hydration products and potentially leading to the filling of the pores. The production of a denser, close-textured structure of CFBFABC pastes containing 10\% CFBFA increased the rate at which cement particles were hydrated. This increase led to a more densified and more homogeneous system and a considerable increase in the long-term strength. CFBFABC pastes containing $10 \%$ CFBFA did not exhibit large decreases in the gel/space ratio. The CFBFABC pastes containing 10\% CFBFA did not exhibit any major decrease in the gel/space ratio. Furthermore, CFBFA has the potential, as a pozzolanic material, partially to replace ordinary Portland cement.

\section{CONCLUSION}

The results of this study can be summarized as follows. The initial and final setting time of CFBFABC pastes with CFBFA retards with an increasing CFBFA content. At the ages of 90 days, CFBFABC pastes containing 10\% CFBFA exhibited a compressive strength similar to that of OPC pastes. X-ray diffraction peaks indicated the presence of portlandite, ettringite, and unreacted $\mathrm{C}_{3} \mathrm{~S}\left(32.6^{\circ}\right)$ and $\mathrm{C}_{2} \mathrm{~S}$ $\left(41.9^{\circ}\right)$. The gel/space ratio of the CFBFABC pastes increased with the curing time and decreased as the CFBFA content increased. The gel/space ratio increased with the curing time because of the progress of hydration, which led to some of the pores being filled. At the ages of 90 days, the gel/space ratio of the CFBFABC pastes containing $10 \%$ CFBFA increased to approximately $14 \%$, perhaps because of the initial attack of CFBFA, which played a major role in the formation of C-S-H and the consumption of $\mathrm{Ca}(\mathrm{OH})_{2}$. It exhibited favorable mechanical characteristics were observed when the mixing ratio of CFBFA was $10 \%$. Furthermore, CFBFA has the potential, as a pozzolanic material, partially to replace ordinary Portland cement.

\section{CONFLICT OF INTEREST}

The authors confirm that this article content has no conflict of interest.

\section{ACKNOWLEDGEMENTS}

Declared none.

\section{REFERENCES}

[1] E. J. Anthony, and D. L. Granatstein, "Sulfation phenomena in fluidized bed combustion systems," Prog. Energy Combust. Sci., vol. 27, no. 2, pp. 215-236, 2001. 
[2] E. J. Anthony, "Fluidized bed combustion of alternative solid fuels, status, successes and problems of the technology," Prog. Energy Combust. Sci., vol. 21, no. 3, pp. 239-268, 1995.

[3] G. H. Sheng, Q. Li, J. P. Zhai, and F. H. Li, "Self-cementitious properties of fly ashes from CFBC boilers co-firing coal and highsulphur petroleum coke," Cement Concr. Res., vol. 37, pp. 871876, 2007.

[4] J. Iribarne, A. Iribarne, J. Blondin, and E. J. Anthony, "Hydration of combustion ashes - a chemical and physical study," Fuel, vol. 80, pp. 773-784, 2001

[5] H. M. Hsu, A. Cheng, and S. J. Chao, "Reuse the bed ash from circulating fluidized bed combustion on mortar mixture," J. Marine Sci. Technol., vol. 18 , no. 4, pp. 620-628, 2010.

[6] H. M. Hsu, "Effects of circulating fluidized bed combustion fly ash on the properties of alkali-activated slag cement mortars," $J$. Marine Sci. Technol., vol. 20, no. 2, pp. 223-232, 2012.

[7] M. O'Farrell, S. Wild, and B. B. Sabir, "Resistance to chemical attack of ground brick-PC mortar Part II. Synthetic seawater," $\mathrm{Ce}$ ment Concr. Res., vol. 30, pp. 757-765, 2000.

[8] C. S. Shon, A. K. Mukhopadhyay, D. Saylak, D. G. Zollinger, and G. G. Mejeoumov, "Potential use of stockpiled circulating fluidized bed combustion ashes in controlled low strength material (CLSM) mixture," Construct. Build. Mater., vol. 24, pp. 839-847, 2010.

[9] R. E. Conn, K. Sellakumar, and A. E. Bland, "Utilization of CFB Fly Ash for Construction Applications," In: Proceedings of the $15^{\text {th }}$ International Conference on Fluidized Bed Combustion, 1999.
[10] E. J. Anthony, E. E. Berry, J. Blondin, E. M. Bulewicz, and S. Burwell, "LIFAC ash - strategies for management", Waste Manage., vol. 25 , no. 3, pp. 265-679, 2005.

[11] G. Sheng, Q. Li, J. Zhai, and F. Li, "Self-cementitious properties of fly ashes from CFBC boiler co-firing coal and high-sulphur petroleum coke," Cement Concr. Res., vol. 37, pp. 871-876, 2007.

[12] K. L. Lin, N. F. Wang, J. L. Shie, T. C. Lee, and C. Lee, "Elucidating the hydration properties of paste containing thin film transistor liquid crystal display waste glass," J. Hazard. Mater, vol. 159, pp. 471-475, 2008

[13] Y. Shen, J. Qian, and Z. Zhang, "Investigations of anhydrite in CFBC fly ash as cement retarders," Construct. Build. Mater., vol. 40, pp. 672-678, 2013

[14] R. R. Menezes, M. I. Brasileiro, L. N. L. Santana, G. A. Neves, H. L. Lira, and H. C. Ferreira, "Utilization of kaolin processing waste for the production of porous ceramic bodies," Waste Manage. Res., vol. 26, pp. 362-368, 2008.

[15] Y. Shen, J. Qian, and Z. Zhang, "Investigations of anhydrite in CFBC fly ash as cement retarders," Construct. Build. Mater., vol. 40, pp. 672-678, 2013.

[16] G. Sheng, J. Zhai, Q. Li, and F. Li, "Utilization of fly ash coming from a CFBC boiler cofiring coal and petroleum coke in Portland cement," Fuel, vol. 86, pp. 2625-2631, 2007.

[17] T. Wu, M. Chi, and R. Huang, "Characteristics of CFBC fly ash and properties of cement-based composites with CFBC fly ash and coal-fired fly ash," Construct. Build. Mater., vol. 66, pp. 172-180, 2014.

(C) Lin et al.; Licensee Bentham Open.

This is an open access article licensed under the terms of the Creative Commons Attribution Non-Commercial License (http://creativecommons.org/licenses/ by-nc/3.0/) which permits unrestricted, non-commercial use, distribution and reproduction in any medium, provided the work is properly cited. 